\title{
Fracture Behavior Analysis of Semi-Circular Bending Test
}

\author{
David Renteria ${ }^{1}$, Shadi Saadeh $^{2, *}$, and Enad Mahmoud ${ }^{3}$ \\ ${ }^{1}$ Terracon Consultants Inc, 5307 Industrial Oaks Blvd Ste. 160, Austin, TX 78735 \\ ${ }^{2}$ Department of Civil Engineering and Construction Engineering Management, California State University, Long Beach, CA90840 \\ ${ }^{3}$ Pavement Analysis \& Design, TxDOT - Maintenance Division, 200 E. Riverside, Austin, TX 78704
}

\begin{abstract}
The objective of this paper is to investigate the effect of air voids on the fracture properties of asphalt mixtures using SCB test in Discrete Element Method (DEM). Superpave and Coarse Matrix High Binder (CMHB) mixtures gradation were used to generate the percentages of aggregate, mastic, and air voids within the specimens. Aggregates and air voids were randomly generated for each asphalt mixture case. Model results illustrate that the crack initiation and propagation is controlled by the location of the aggregate particles and air voids in the mixture. Additionally, the absence of air voids above the tip of the notch increases the stiffness of the sample and increase its resistance to failure. The novelty of using DEM and the random generation technique for generating numerical specimens proved to be a useful approach in investigating the properties of the mastic, aggregate and interface as they relate to fracture of asphalt mixtures.
\end{abstract}

\section{Introduction}

There are several asphalt laboratory cracking tests that provide insights into the performance of asphalt pavements. The SCB test has been extensively used lately since laboratory and field asphalt specimens can directly be tested due to the simplicity and easy set-up of the SCB. Many studies demonstrated that the SCB would be a great candidate as a cracking test to assist in the fracture analysis of asphalt mixtures under different loading modes [1]. Based on the current literature, the modeling methods for the SCB test have been concentrated in two main approaches, the DEM and the Finite Element Method (FEM) [2-5]. Additionally, image processing and random generation techniques have been used to generate the internal structure of the asphalt models $[6,7]$. The aggregate characteristics such as angularity and size have been well studied to see their effect on the stiffness of asphalt mixtures [8, 9]. Moreover, laboratory experiments showed the impact of air void content and distribution in asphalt mixtures [10].

In DEM, objects can be composed of several particles, which interact with each other at contact points, thus forces and displacements are transferred through the sample via the contact points between particles. The contact behavior is described using three models: slip, stiffness, and bonding. The first two models are directly related to the slipping and friction between discrete elements. The bonding model is the material's strength parameter and it can be envisioned as a pair of elastic springs with normal and shear stiffnesses acting at the contact point [11]. For this study, the linear contact model which includes the contact bond behavior is used. The time-dependent asphalt behavior in DEM is simulated by using the Burger's contact model, which uses the Kelvin and Maxwell models connected in series in the normal and shear direction. The Kelvin model combines linear springs and dashpots as components acting in parallel. On the other hand, the Maxwell model incorporates the same rheological components but acting in series [12].

\section{Objectives}

The main objective of this paper is to investigate the effect of air voids on the fracture properties of asphalt mixtures using SCB test in DEM that considers the modelling of aggregates, mastic, and air voids and specimen random generation technique. A list of tasks was followed to successfully simulate the asphalt mixture components; it is as follows:

- Generation of SCB test: a proper representation of the aggregate, mastic, air voids, and shape of the test model in DEM.

- Asphalt Mixtures and characteristics: Superpave and Coarse Matrix High Binder (CMHB) mixtures and their percentages of aggregate material, mastic, and air voids in the model. The properties of the mastic for each mixture. The selection of the aggregate materials and their generation in the model from twodimensional images.

- Material and model calibration: The DEM material properties for each mixture was obtained from model calibration.

- SCB analysis: Damage in the model was characterized based on the fracture behavior for each asphalt mixture.

\footnotetext{
* Corresponding author: shadi.saadeh $@$, csulb.edu
} 


\section{DEM model and materials generation}

The generation of the SCB model included several steps in the numerical software since there is not a single command that can recreate such a shape. Walls in DEM are used to induce loading, define boundary conditions or geometric shapes. In this case, walls were created to aid in the representation of the SCB test. The radius of the circle geometry was set to $75 \mathrm{~mm}$. The rectangle geometry was used to simulate the notch in the SCB; its dimensions were $2 \mathrm{~mm}$ wide and $30 \mathrm{~mm}$ long (see Figure 1). The target porosity used for this study was 0.1 and the ball radii was from 0.2 to $0.6 \mathrm{~mm}$.

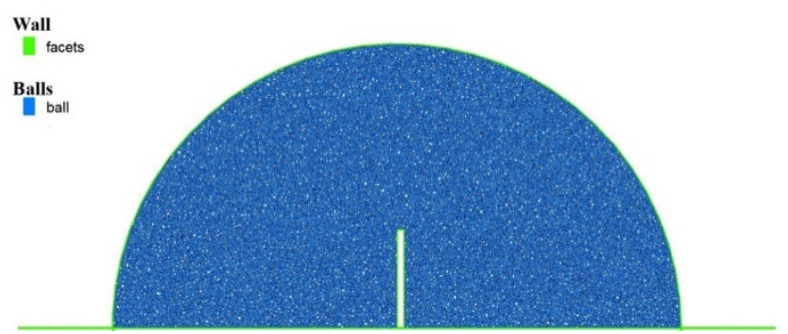

Fig. 1. SCB model characteristics.

\subsection{Asphalt mixture content}

The aggregate gradation of the two mixtures is different and this must be considered when the aggregate phase is generated into the homogeneous SCB model. These parameters as well as the percentage of the asphalt binder and air voids were obtained from the literature [13]. Superpave is a fine-graded mixture that contains $35 \%$ of coarse aggregate and $65 \%$ of fine aggregate. CMHB is a coarse-graded mix composed of $63 \%$ of coarse aggregate and $37 \%$ of fine aggregate. Three different types of aggregate material were used and these include granite, hard limestone, and soft limestone. It is important to mention that the air void content in both mixtures was $4 \%$ and it was based on the literature review [13].

\subsection{Aggregate particles}

Aggregate material was modeled from two-dimensional aggregate images that were obtained from the Aggregate Imaging Measurement System (AIMS) database. The total number of images used in this study was 238. These images were classified with respect to their angularity index as low and high angular aggregates. The range of the angularity index from these images range from 0 to 5000. The ranges of the angularity index for low and high angularity was in accordance with [14]. Therefore, aggregate images with an angularity index from 0 to 2100 were grouped as low angular aggregates, and aggregate images with an angularity index above 2100 were classified as high angular aggregates.

\subsection{DEM material and model parameters}

In DEM, the material laboratory test parameters cannot be simply used as an input to describe the mechanical behavior of the aggregate and mastic. Since the modeling of an object in Particle Flow Code - 2 dimensional (PFC2D) is based on an assembly of discrete elements, it is important to get the actual response of the micro-components to loading. To do his, aggregate calibration tests were performed in PFC2D to determine the numerical aggregate and mastic properties.

\subsection{Rock masses and mastic properties}

The tensile and compression strengths were determined using the splitting tensile test and the compression test, respectively. The calculation of the material's stiffness was obtained from nondestructive testing (NTD) techniques, including seismic and ultrasonic methods.

The numerical aggregate properties were used as an input in the calibration of the asphalt mixtures. This calibration was done in PFC2D by modeling the indirect tensile test. The internal structure of the asphalt mixtures was captured using X-ray images. A MATLABTM routine was necessary to replicate the material phases (aggregate, mastic) into the model.

\subsection{Interface properties}

In addition to the study of the effect of air voids in the mixture, another important aspect that was considered was the effect of the interface (between aggregate and mastic) properties on the fracture behavior in the SCB. The modulus of elasticity was taken as the average of the mastic and the aggregate parameters, and the magnitude of the contact bond at the interface was set to twice of the mastic $[15,16]$. The material property depicted in Figure 2 was the modulus of elasticity. Interface contacts between the aggregate and asphalt discrete elements are shown as black lines, and purple circles represent air voids in the system.

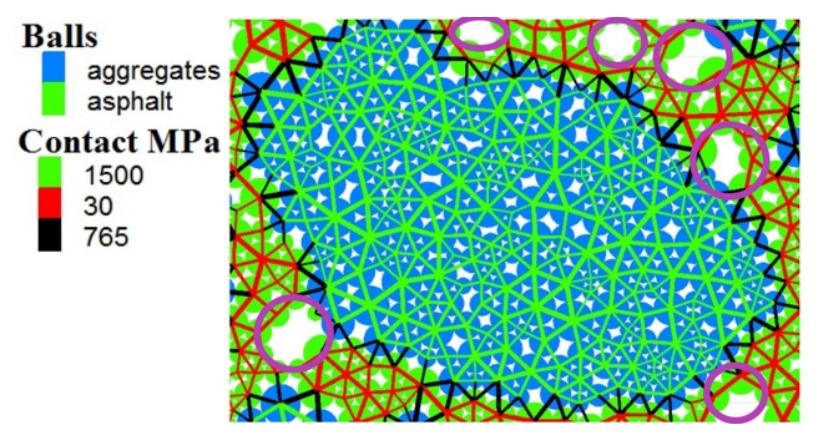

Fig. 2. Contact bond properties within the aggregate, in the mastic, and at the interface.

\section{SCB results}

The procedure for testing each specimen - case is simple. First, the internal structure of the SCB is generated based on the two angularity sets. Second, contact properties for aggregate, mastic and interface are given for each mixture - case. Third, after assigning 
material properties, a wall body is induced into the model to induce loading.

The analysis of this paper consists of having two mixture gradations, three aggregates types, two aggregate angularities, and two interface contact properties. The total number of simulations generated for each mixture combination was 100. Therefore, Superpave and CMHB simulations consisted of 1200 specimens for each asphalt mixture. The interface properties are categorized into two groups, mastic mastic and modified. Mastic - mastic indicates that the properties at the interface are set the same as the properties between the contact of two mastic discrete elements. On the other hand, modified interface properties imply that these parameters were changed according with $[15,16]$.

\subsection{DEM results with interface properties as mastic-mastic}

Figure 3 makes a comparison of using high and low angular aggregates for CMHB mixtures. The performance for every CMHB - aggregate combination was better when high angular aggregates were used in the mixture. Superpave samples do not show this angularity effect on their mixtures. One reason could be due to the percentage of aggregate content in the model. The aggregate content in Superpave leads to large areas covered with mastic phase and few chances for aggregates to interlock with each other, maximize the material stiffness of the sample, and have a more uniform distribution of the internal forces [8].

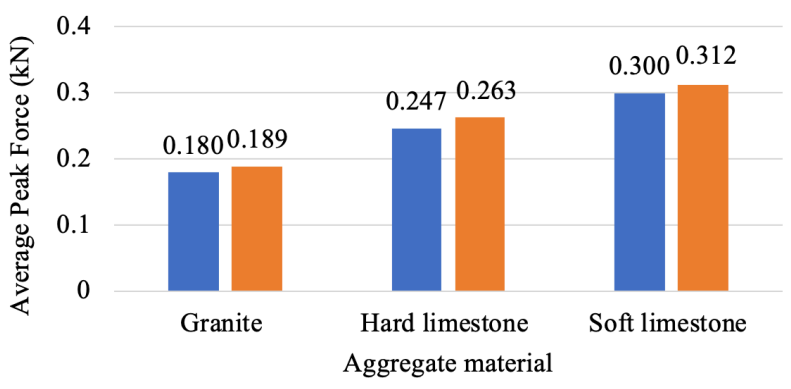

- Low aggregate angularity $\quad$ High aggregate angularity

Fig. 3. Comparison of high and low angular aggregates in CMHB mixtures.

The following examples present the material ranking from the two asphalt mixtures, angularity indexes, and aggregate types under this subheading. The highest maximum force among these samples was seen in Superpave-granite combination, while the lowest test performance was from the CMHB-granite mixture. In Figure 4-a, one aggregate particle that was randomly generated by the system at the tip of the notch forced the crack to go slightly to the right and through the interface between the aggregate and mastic phases. Since there were not any air voids near the crack region, as circled in red, the crack went through the aggregate particle and continued in the mastic region. The total applied load in this specimen to achieve failure was $0.57 \mathrm{kN}$. On the other hand, a large concentration of air voids was located above the tip of the notch for CMHB-granite case, Figure 4-b. Due to this, the crack in this sample developed rapidly through the air voids with a minimal force required to reach failure. The total applied load for CMHB-granite was $0.087 \mathrm{kN}$.

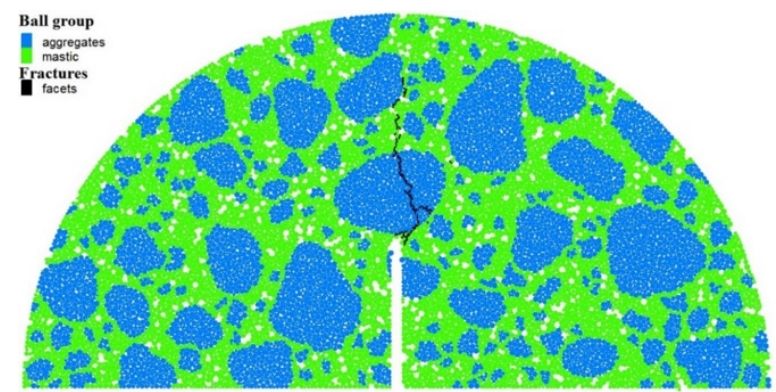

(a)

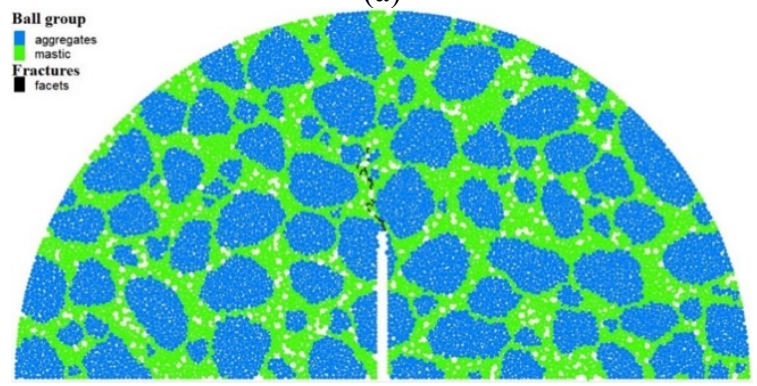

(b)

Fig. 4. a) Cracking in Superpave - granite sample, b) cracking in CMHB - granite sample.

\subsection{DEM results with modified interface properties}

The aggregate angularity effect was also seen in asphalt specimens with modified interface properties. However, asphalt specimens with modified interface properties showed a better performance compared with the results obtained where the interface properties were set as mastic - mastic. Figure 5 describes the average peak force differences when two types of interface are used. This behavior was observed in both mixture gradations when comparing results under the same aggregate angularity. This shows the importance of calculating appropriately the properties at the interface for numerical asphalt models.

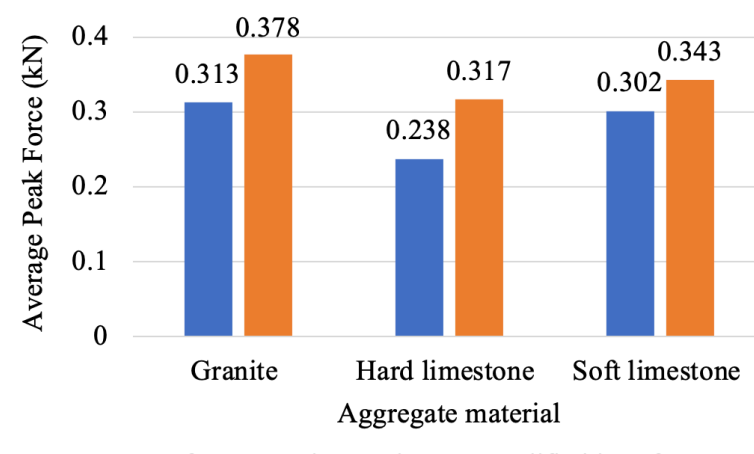

Interface - mastic-mastic modified interface

Fig. 5. Comparison of the properties at the interface for Superpave mixtures with high aggregate angularity. 
Table 1 shows the effect of aggregate angularity and modified interface properties for the CMHB mixtures. Since most of the breakage occurred in the mastic phase, the average peak forces ranked in the same order as the contact bond strength values of the mastic from the numerical calibration. The highest average peak force values for both angularities and interface contact properties can be found when soft limestone material is used. On the other hand, CMHB-granite mixtures yield the lowest average peak forces. The soft limestone aggregate (alone) properties were the lowest values compared to the other aggregate materials. Nevertheless, the superior performance of both mixtures gradation using soft limestone properties into the aggregate phase is due to the low modulus of elasticity of the aggregate particles that reduces the stress concentrating effects on the mastic and yield high fracture stresses on the mastic particles.

Table 1. Average Peak Forces for CMHB Combinations.

\begin{tabular}{|c|c|c|c|}
\hline $\begin{array}{l}\text { Mixture - } \\
\text { Aggregate }\end{array}$ & $\begin{array}{l}\text { Angularity } \\
\text { Index }\end{array}$ & $\begin{array}{l}\text { Interface } \\
\text { Contact } \\
\text { Property }\end{array}$ & $\begin{array}{c}\text { Average Peak } \\
\text { Force (N) }\end{array}$ \\
\hline $\begin{array}{l}\text { CMHB- } \\
\text { Granite }\end{array}$ & $>2100$ & mastic - mastic & 189.2 \\
\hline $\begin{array}{l}\text { CMHB-Hard } \\
\text { limestone }\end{array}$ & $>2100$ & mastic-mastic & 262.9 \\
\hline $\begin{array}{l}\text { CMHB-Soft } \\
\text { limestone }\end{array}$ & $>2100$ & mastic-mastic & 312.1 \\
\hline $\begin{array}{l}\text { CMHB- } \\
\text { Granite }\end{array}$ & $>2100$ & $\begin{array}{l}\text { modified } \\
\text { interface }\end{array}$ & 240.6 \\
\hline $\begin{array}{l}\text { CMHB-Hard } \\
\text { limestone }\end{array}$ & $>2100$ & $\begin{array}{l}\text { modified } \\
\text { interface }\end{array}$ & 317.8 \\
\hline $\begin{array}{l}\text { CMHB-Soft } \\
\text { limestone }\end{array}$ & $>2100$ & $\begin{array}{l}\text { modified } \\
\text { interface }\end{array}$ & 350.9 \\
\hline $\begin{array}{l}\text { CMHB- } \\
\text { Granite }\end{array}$ & $<2100$ & mastic-mastic & 180.4 \\
\hline $\begin{array}{l}\text { CMHB-Hard } \\
\text { limestone }\end{array}$ & $<2100$ & mastic - mastic & 246.6 \\
\hline $\begin{array}{l}\text { CMHB-Soft } \\
\text { limestone }\end{array}$ & $<2100$ & mastic-mastic & 300.2 \\
\hline $\begin{array}{l}\text { CMHB- } \\
\text { Granite }\end{array}$ & $<2100$ & $\begin{array}{l}\text { modified } \\
\text { interface }\end{array}$ & 233.0 \\
\hline $\begin{array}{l}\text { CMHB-Hard } \\
\text { limestone }\end{array}$ & $<2100$ & $\begin{array}{l}\text { modified } \\
\text { interface }\end{array}$ & 313.2 \\
\hline $\begin{array}{l}\text { CMHB-Soft } \\
\text { limestone }\end{array}$ & $<2100$ & $\begin{array}{l}\text { modified } \\
\text { interface }\end{array}$ & 355.0 \\
\hline
\end{tabular}

\section{Conclusions}

The SCB test was modeled in DEM using PFC2D. Heterogeneous SCB models which include aggregate, air voids, and mastic phases were generated using the random generation technique. Superpave and CMHB mixtures gradation included different aggregate type, angularity, and interface contact properties. The model of the SCB consisted of an assembly of a dense-packing of non-uniform circular discrete elements. Aggregate phase was represented in the model through a series of steps to be able to generate particles with different shapes, angularities, and sizes. For simplicity, a uniform size was given to the air voids generated in the mixtures.
The linear contact bond model was used to simulate the mechanical behavior of the aggregate and mastic phases and the regions between them as well. DEM of aggregate and asphalt calibration tests were performed to determine their contact bond parameters and modulus of elasticity. The number of samples for each mixture gradation was 1200 . Based on the results, the following conclusions can be drawn:

- DEM models with interface properties set as mastic - mastic

- Air voids in the mixture define the crack path

- The average peak forces ranked in a similar order to that of the contact bond strength values of the mastic from the numerical calibration for the CMHB mixtures

- It was observed that the use of angular aggregates increased the stiffness only for CMHB specimens

- The angularity effect in CMHB samples did not appear in Superpave mixtures due to the difference in aggregate content in the model

- The amount of aggregates and air voids located near the tip of the notch have a significant impact on crack initiation and propagation

- Cracking developed in the interface allows the sample to support more load

- DEM models with modified interface properties

- The effect of the air voids within the model and near the tip of the notch was also seen for these types of mixtures

- Aggregate particles randomly generated at the tip of the notch made the sample to carry more load than specimens where the crack started between two mastic discrete elements

○ The aggregate angularity still influenced on the performance of asphalt pavements

- Modified interface properties resulted in the increase in the average peak forces for both mixtures gradation

- Specimens with cracking at the interface yielded the best results in terms of the total applied load

- Interface properties effect on fracture behavior

- Mastic-Mastic interface

- The crack path is affected by air voids and aggregate location. The crack tended to develop in the mastic phase by going through air voids. The peak force for samples with cracking at the interface is higher than for samples with cracking through mastic.

- Modified properties

- The fracture behavior for this type of samples is the same as for the samples with mastic mastic interface. The main difference was the strong relationship between the higher peak sample values with samples cracking at the interface. 


\section{Disclaimer}

The contents of this paper reflect the views of the authors who are responsible for the facts and accuracy of the data presented herein and do not necessarily reflect the official views or policies of any agency or institute. This paper does not constitute a standard, specification, nor is it intended for design, construction, bidding, contracting, tendering, certification, or permit purposes. Trade names were used solely for information purposes and not for product endorsement or certification.

\section{References}

1. Saha, G., and Prapoorna, B.K. (2015). Fracture properties of asphalt mixtures using semi-circular bending test: A state-of-the-art review and future research. Construction and Building Materials. 105, 103-112.

2. Castillo, D., Caro, S., Darabi, M., and Masad, E. (2015). Studying the effect of microstructural properties on the mechanical degradation of asphalt mixtures. Construction and Building Materials. 93, 70-83.

3. Huang, B., Shu, X., and Zuo, G. (2013). Using notched semi circular bending fatigue test to characterize fracture resistance of asphalt mixtures. Engineering Fracture Mechanics. 109, 78-88.

4. Lancaster, I.M., Khalid, H.A., and Kougioumtzoglou, I.A. (2013). Extended FEM modelling of crack propagation using the semicircular bending test. Construction and Building Materials. 48, 270-277.

5. Mahmoud, E., Saadeh, S., Hakimelahi, H., and Harvey, J. (2013). Extended finite - element modelling of asphalt mixtures fracture properties using the semi - circular bending test. Road Materials and Pavement Design.

6. Khattak, M.J., Khattab, A., Rizvi, H.R., Das, S., Bhuyan, M.R. (2014). Imaged-based discrete element modeling of hot mix asphalt mixtures. Materials and Structures.

7. Zelelew, H.M., and Papagiannakis, A.T. (2011). A volumetrics thresholding algorithm for processing asphalt concrete X-ray CT images. International Journal of Pavement Engineering. 12(6), December 2011, 543-551.

8. Dondi, G., Simone, A., Vignali, V., and Manganelli, G. (2012). Discrete Element Modelling of Influences of Grain Shape and Angularity on Performance of Granular Mixes for Asphalts. Social and Behavioral Sciences. 533, 399-409.

9. Yu, H., and Shen, S. (2011). Impact of aggregate packing on dynamic modulus of hot mix asphalt mixtures using three dimensional discrete element method. Construction and Building Materials. 26, 302-309.

10. Chen, J., Huang, B., and Shu, X. (2013). Air void Distribution Analysis of Asphalt Mixture Using
Discrete Element Method. Journal of Materials in Civil Engineering, 25(10), ASCE.

11. Itasca Consulting Group, Inc. (2014). PFC Particle Flow Code, Ver. 5.0. Minneapolis: Itasca.

12. Cai, W., McDowell, G.R., Airey, G.D. (2014). Discrete element visco-elastic modelling of a realistic graded asphalt mixture. Soils and Foundations. 54(1), 12-22.

13. Alvarado, C., Mahmoud, E., Abdallah, I., Masad, E., Nazarian, S., Langford, R., Tandon, V., and Button, J. (2007). Feasibility of quantifying the role of coarse aggregate strength on resistance to load in HMA. TxDOT Project No. 0-5268 and Research Report No. 0-5268.

14. Masad, E., Luce, A., and Mahmoud, E. (2006). Implementation of AIMS in measuring aggregate to polishing, abrasion and breakage. Texas Transportation Institute. The Texas A\&M University System.

15. Abbas, A. (2004). Simulation of the Micromechanical Behavior of Asphalt Mixtures using the Discrete Element Method. Ph.D. dissertation, Washington State Univ., Pullman, WA

16. Khorasani, S., Masad, E., Kassem, E., and Abu AlRub, R.K. (2013). Nano-Mechanical Characterization of Mastic, Aggregate, and Interfacial Zone in Asphalt Composites. Journal of Testing and Evaluation, 41(6), 1-9. 